\title{
The Effect of Adding Ketamine to Bupivacaine in Ultrasound Guided Ilioinguinal and Iliohypogastric Nerve Block for Inguinal Hernia Operations
}

\author{
NOHA O. AL-MOBAYAD, M.Sc.; HALA M. EL-GENDY, M.D.; HODA A. EZZ, M.D. and \\ MOHAMMED G. AYAD, M.D. \\ The Department of Anesthesiology and Surgical Intensive Care, Faculty of Medicine, Tanta University, Tanta, Egypt
}

\begin{abstract}
Background: Chronic pain occurs in $5-10 \%$ after the inguinal hernia repair that creates an important problem. Peripheral nerve blocks with local anesthetics are a method that may be used in inguinal hernia surgeries. Iliohypogastric (IH) and Ilioinguinal (II) nerve blocks are used for this purpose.

Aim: Our aim is to evaluate the effect of adding ketamine to bupivacainein ultrasound guided ilioinguinal and iliohypogastric nerve block in patients scheduled for inguinal hernia repair.

Patients and Methods: This study was carried out on 90 patient, 18-60 years, ASA I-II, scheduled for elective inguinal hernia repair under general anesthesia with ilioinguinal and iliohypogastric nerve block. Patients were randomized into two equal groups (45 patients in each group): Group 1: Received given $2 \mathrm{mg} / \mathrm{kg}$ of $0.5 \%$ bupivacaine in the block) and Group II (given $2 \mathrm{mg} / \mathrm{kg}$ of $0.5 \%$ bupivacaine with ketamine $2 \mathrm{mg} / \mathrm{kg}$ in the block) 45 patients the following parameters were compared between the 2 groups: Vital signs (heart rate, mean arterial pressure), Visual Analogue Scale (VAS), the first time for resuce analgesia, dose of rescue analgesia (morphine), incidence of Post-Operative Nausea and Vomiting (PONV) using neumeric rank score and undesirable side effect.
\end{abstract}

Results: There were no significant difference between the two studied groups regarding demographic data, vital signs, Post-Operative Nausea and Vomiting (PONV) and undesirable side effects. The visual analogue scale showed that pain began earlier and more sever in group 1than in Group II. Total dose of rescue analgesia (morphine) was significantly higher in Group I than Group II. The first time for resuce analgesia was earlier in Group I than Group II.

Conclusion: Patients undergoing inguinal hernia repair surgery, addition of ketamine $2 \mathrm{mg} / \mathrm{kg}$ to bupivacaine in ultrasound guided ilioinguinal and iliohypogastric nerve block produce more effective postoperative analgesia as indicated by lower VAS scale and the prolonged duration of sensory block compared to bupivacaine alone.

Correspondence to: Dr. Noha O. Al-Mobayad,

The Department of Anesthesiology and Surgical Intensive Care, Faculty of Medicine, Tanta University, Tanta, Egypt
Key Words: Inguinal hernia - Ketamine-bupivacaine - Ilioinguinal-Iliohypogastric nerve block.

\section{Introduction}

INGUINAL hernia repair is one of the world's most common surgical procedures with over one million surgeries accomplished per year in Europe and the United States, mainly as an out-patient regime [1]. Post-operative pain is localized at the territory innervated by the ilioinguinal nerve, being moderate-severe $[2,3]$ and causing an increase in morbidity, extended hospital stay and unexpected hospitalization with consequently increasing expenses $[4,5]$.

Similarly, inadequate perioperative pain control is an important factor for persistent pain, resulting in chronic pain in $10-50 \%$ of the patients and limitation for daily activities in almost a third of them [6,7]. Chronic pain occurs in 5-10\% after the inguinal hernia repair that creates an important problem [8] . A significant part of pain after hernia surgery is caused by the abdominal wall incision [9].

Post-operative pain management in cases that undergo abdominal surgery is complicated. Despite the effective pain management methods, the frequency of moderate or severe pain is found to be $30-75 \%$ [10].

Various methods and medications are used in postoperative pain management. Peripheral nerve blocks with local anesthetics are a method that may be used in inguinal hernia surgeries. Iliohypogastric (IH) and Ilioinguinal (II) nerve blocks are used for this purpose [11,12]. 
Ultrasonography has become a routine technique for regional anaesthetic nerve block. Several studies have shown that direct visualization of the distribution of local anaesthetics with highfrequency probes can improve the quality and avoid the complications of upper/lower extremity nerve blocks and neuroaxial techniques. Ultrasound guidance enables the anaesthetist to secure an accurate needle position and to monitor the distribution of the local anaestheticin real time. The advantages over conventional guidance techniques, such as nerve stimulation and loss of-resistance procedures, are significant. Considering their enormous potential, these techniques should have a role in the future training of anaesthetists [13]

Ketamine is a noncompetitive antagonist of the $\mathrm{N}$-methyl-D aspartate (NMDA) receptor. It has been reported to enhance the analgesic effects of local anesthetics. Also, it is used for premedication, sedation, induction and maintenance of general anesthesia. Central, regional and local anesthetic and analgesic properties have been reported for ketamine [14,15]

The aim of the study is to evaluate the effect of adding ketamie to bupivacaine in ultrasound guided ilioinguinal and iliohypogastric nerve block in patients scheduled for inguinal hernia repair surgery.

\section{Patients and Methods}

After obtaining the Research Ethics Committee approval and informed written consent was taken from patients, a prospective clinical trial was carried out in Tanta University Hospitals in General Surgery Department from Dec. 2016-June 2017 on 90 patients of both sex, 18-60 years old, ASA I and II and scheduled for elective inguinal hernia repair surgery. Refusal of patients, history of bleeding disorders, mental dysfunction, drug addiction and allergy of local anesthetic drugs were excluded from the study.

Patients were randomized into two equal groups by using sealed opaque envelop (45 patients in each group) according to the drugs used for ilioinguinal and iliohypogastric nerve block. Group 1: Patient received $2 \mathrm{mg} / \mathrm{kg}$ of $0.5 \%$ bupivacaine. Group 11: Patient received $2 \mathrm{mg} / \mathrm{kg}$ of $0.5 \%$ bupivacaine with ketamine $2 \mathrm{mg} / \mathrm{kg}$.

The anesthetic solution was prepared by another doctor, not involved in the study. All observations were carried out by a single investigator, who was blinded to the treatment groups.
Medical and surgical histories of the patients were evaluated, clinical examination of the patient was performed, routine laboratory investigations were evaluated including complete blood picture, prothrombin time and activity, liver and renal functions, then on arrival to the operating room routine standard monitoring in the form of pulse oximetery, electrocardiogram, end tidal carbon dioxide, non-invasive blood pressure was instituted and wide pore intravenous cannula was inserted in both groups.

General anaesthesia was induced intravenously using $2 \mathrm{Mic} / \mathrm{kg}$ of fentanyl and $2 \mathrm{mg} / \mathrm{kg}$ of propfol, tracheal intubation was facilitated by $0.1 \mathrm{mg} / \mathrm{kg}$ cisatracurium and muscle relaxation was maintained with additional doses $0.02 \mathrm{mg} / \mathrm{kg}$. Anaesthesia was maintained with isoflurane $1.5-2 \%$. At the end of the procedure the residual neuromuscular blockade was antagonized with neostigmine $0.05 \mathrm{mg} / \mathrm{kg}$ and atropine $0.01 \mathrm{mg} / \mathrm{kg}$.

Before extubation patient was placed in a supine position, gel applied to the ultrasound probe which was held by an assistant. The area of the block was sterilized with betadine solution. Anterior Superior Iliac Spine (ASIS), ilioinguinal ligament and line connecting the ASIS with the umbilicus are the anatomical landmarks for performing this block. A linear probe of high frequency $(6-13 \mathrm{MHz})$ was oriented perpendicular to the inguinal ligament and was first positioned so the lateral aspect of the probe lied on top of the iliac crest. The ASIS is the standard starting position from which the transducer was moved slowly along the ASIS-umbilicus line. Ilioinguinal and iliohypogastric nerves are in the fascial plane between the external oblique and internal oblique and between internal oblique and transversus abdominus muscle. The ilioinguinal nerve is usually found close to the iliac crest and the iliohypogastric nerve lies medial to it. The peritoneal fascia and peritoneal cavity lie deep to the transversus abdominus muscle and peristaltic movements of the bowel could be detected. The needle was advanced to the fascial plane between the internal oblique and transversus abdominal muscles and was placed adjacent to the ilioinguinal and iliohypogastric nerves which is enclosed in the fascial split. After marking the ASIS and drawing a line between the ASIS and the umbilical button, the patient's lower quadrant should be sterilely prepared. The injection site is located 3 $\mathrm{cm}$ medial and above the ASIS. At this point right placement was checked by injecting a small amount of saline, producing a hypoechoic expansion of the area between the fascia of the transversus abdominus and internal oblique muscle. 
Then, in Group I: Injection of total volume $30 \mathrm{ml}(27 \mathrm{ml}$ of $0.5 \%$ bupivacaine $+3 \mathrm{ml}$ saline $)$. In Group II: Injection of total volume $30 \mathrm{ml}(27 \mathrm{ml}$ of $0.5 \%$ of bupivacaine + ketamine $3 \mathrm{mg} / \mathrm{kg}$ ). Trade Name: Katalar, vial containing: $10 \mathrm{cc}, 1 \mathrm{cc}=50 \mathrm{mg}$.

Measurements: Patient's demographic data, time to first request for analgesia, rescue analgesia (morphine) if score is $>3$ analgesia needed in the form of morphine $2 \mathrm{mg}$ if patient body weight $<60$ $\mathrm{kg}, 3 \mathrm{mg}$ if patient body weight $>60 \mathrm{~kg}$ lock out interval 10min, until VAS $<3$. Undesirable sideeffects (headache, urinary retention and hemodynamic changes like bradycardia or hypotension) were reported during the first 24 hours postoperative. Post-Operative Nausea \& Vomiting (PONV) was evaluated with a numerical scale from 0 to 3 (0: No nausea; 1 : Mild nausea; 2 : Severe nausea and/ or vomiting in spite of treatment).

The patients were familiarized with a 10-point Verbal Analog Scale (VAS) for pain that ranged from $(0=$ no pain $)$ to $(10=$ the worst imaginable pain). If score is $>4$ analgesia needed in the form of morphine $2 \mathrm{mg}$ if patient body weight $<60 \mathrm{~kg}$, $3 \mathrm{mg}$ if patient body weight $>60 \mathrm{~kg}$ lock out interval $10 \mathrm{~min}$., until VAS $<3$. The time to the first request for analgesia and the total morphine dose was recorded. The VAS was assessed and recorded on arrival to the recovery unit at $4,8,12,18,24 \mathrm{~h}$ after the operation, by an anesthesiologist, who was blinded to the treatment groups his telephone number is given to the patient to call him at any time he felt moderate or severe pain.

Hemodynamic changes as bradycardia was managed by atropine $0.01-0.02 \mathrm{mg} / \mathrm{kg}$. Hypotension by ephedrine $0.3 \mathrm{mg} / \mathrm{kg}$. Privacy of patients and confidentiality of data was maintained by using coding numbers. The obtained data of the study was used in scientific research only.

The sample size calculation is performed using EpI-Info 2002 software statistical package designed by World Health Organization (WHO) and by Centers for Disease Control and Prevention (CDC). The sample size is calculated as $\mathrm{N}>44$ based on the following considerations: $95 \%$ confidence limit, $80 \%$ power of the study. Ratio of the two study group 1:1.

Statistical presentation and analysis was conducted by SPSS V. 24. Results were expressed as means \pm Standard Deviation (SD). Student paired $t$.test: For statistical analysis within the same group. Unpaired $t$-test: Used for comparison of parametric data between the two studied groups. Modified chi-square test for small numbers: For comparison between two groups as regards qualitative data. Whenever any of the expected cells were less than five, Fischer's Exact test with Yates correction was used. Mann Whitney's test was used for comparison of quantitative variables between two groups of not normally distributed data. $p$-value $<0.05$ was considered significant.

\section{Results}

There was no statistical significant difference between the two groups as regards to demographic data (age, sex, weight, ASA status and duration of surgery) (Table 1).

Regarding the comparison of the heart rate and MAP between the two groups: At base line and $4 \mathrm{hr}$ post-operative: There was no significant difference between the two groups, there was significant increase in HR and MAP in Group I compared to Group II with at $8,12,18$ and 24 hours postoperative. (Table 2). Regarding the comparison of pain intensity between the two groups: At $4 \mathrm{hr}$ postoperative: There was no significant difference between the two groups, there was significant difference in pain intensity at $8,12,18,24 \mathrm{hr}$ between both groups Fig. (1). Regarding the comparison of VAS score between the two studied groups: There was significant difference between the changes in the visual analogue pain score in Group I and Group II with pain began earlier and more severe in Group I than Group II Fig. (2).

The dose of postoperative analgesia in the two studied groups revealed that the dose of morphine was significantly higher in Group I than Group II. Comparison between the two groups regarding the first time for rescue analgesia shows significant prolonged duration in Group II compared with Group I and there was no significant difference between both groups regarding PONV (Table 3 ).

Table (1): Demographic data.

\begin{tabular}{llll}
\hline & $\begin{array}{c}\text { Group I } \\
(\mathrm{n}=45)\end{array}$ & $\begin{array}{c}\text { Group II } \\
(\mathrm{n}=45)\end{array}$ & $\begin{array}{c}p- \\
\text { value }\end{array}$ \\
\hline $\begin{array}{l}\text { Age: } \\
\quad \text { Mean } \pm \text { SD }\end{array}$ & $35 \pm 9$ & $32 \pm 10$ & 0.15 \\
$\begin{array}{l}\text { Weight: } \\
\quad \text { Mean } \pm \text { SD }\end{array}$ & $78 \pm 8$ & $78 \pm 9$ & 0.71 \\
$\begin{array}{l}\text { Duration of surgery: } \\
\quad \text { Mean } \pm \text { SD }\end{array}$ & $73 \pm 11$ & $73 \pm 8$ & 0.97 \\
$\begin{array}{l}\text { Gender: } \\
\quad \text { Male: n (\%) }\end{array}$ & $45(100 \%)$ & $45(100 \%)$ & - \\
$\begin{array}{l}\text { ASA: } \\
\quad \text { I: } \mathrm{n}(\%)\end{array}$ & $31(69 \%)$ & $24(53 \%)$ & 0.13 \\
$\quad$ II: n $(\%)$ & $14(31 \%)$ & $21(47 \%)$ & \\
\hline
\end{tabular}

$*$ : $p$-value significant if $<0.05$. 
Table (2): Comparison of the heart rate (beats/min) and MAP $(\mathrm{mmHg})$ between the two groups.

\begin{tabular}{lccl}
\hline & $\begin{array}{c}\text { Group I } \\
(\mathrm{n}=45) \\
\text { Mean } \pm \text { SD }\end{array}$ & $\begin{array}{c}\text { Group II } \\
(\mathrm{n}=45) \\
\text { Mean } \pm \text { SD }\end{array}$ & $\begin{array}{c}p \text { - } \\
\text { value }\end{array}$ \\
\hline Heart rate: & & & \\
Baseline & $78 \pm 10$ & $79 \pm 9$ & 0.70 \\
HR 4h & $79 \pm 9$ & $80 \pm 10$ & 0.60 \\
HR 8h & $83 \pm 9$ & $79 \pm 11$ & $0.03 *$ \\
HR 12h & $89 \pm 8$ & $84 \pm 10$ & $0.02^{*}$ \\
HR 18h & $96 \pm 7$ & $93 \pm 8$ & $0.01^{*}$ \\
HR 24h & $105 \pm 6$ & $100 \pm 6$ & $<0.001^{*}$ \\
MAP: & & & \\
MAP baseline & $78 \pm 11$ & $77 \pm 8$ & 0.74 \\
MAP 4h & $79 \pm 8$ & $76 \pm 10$ & 0.18 \\
MAP 8h & $84 \pm 8$ & $79 \pm 11$ & $0.02^{*}$ \\
MAP 12h & $86 \pm 8$ & $82 \pm 10$ & $0.04^{*}$ \\
MAP 18h & $90 \pm 7$ & $86 \pm 10$ & $0.01 *$ \\
MAP 24h & $95 \pm 7$ & $91 \pm 9$ & $0.009^{*}$ \\
\hline
\end{tabular}

*: Significant at $p$-value $<0.05$ for comparison between the two groups.
Table (3): Comparison between both groups according to the post-operative morphine rescue analgesia, time to first request for analgesia and Post-Operative Nausea \& Vomiting (PONV).

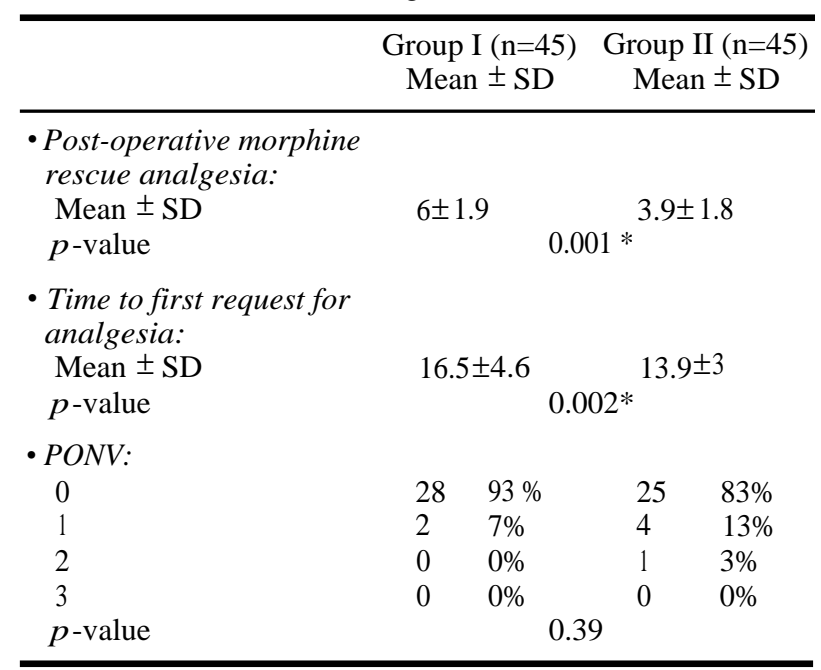

*: Significant at $p$-value $<0.05$ for comparison between the two groups.

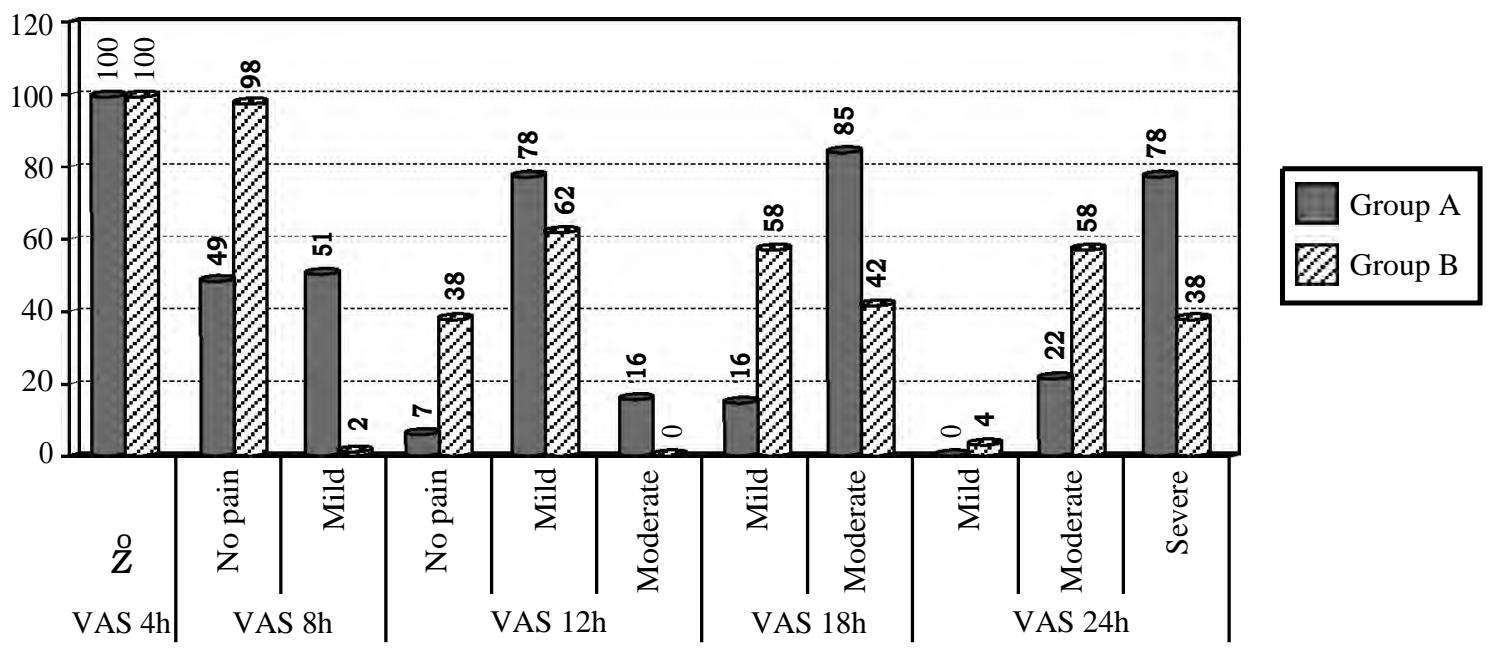

Fig. (1): Pain intensity in the two studied groups at different time measures in both groups.
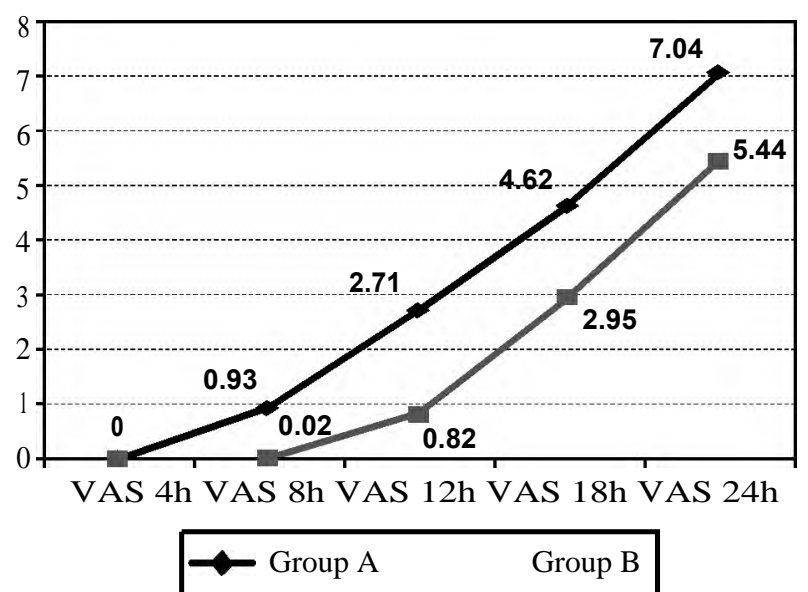

Fig. (2): Mean VAS score at different time measures in both groups.

\section{Discussion}

Various methods and medications are used in post-operative pain management. Peripheral nerve blocks with local anesthetics may be used in inguinal hernia surgeries. Iliohypogastric $(\mathrm{IH})$ and Ilioinguinal (II) nerve blocks are used for this purpose. Iliohypogastric (IH) and Ilioinguinal (II) nerve blocks have been reported to produce excellent post-operative pain control following such treatments as hernia repair and groin surgery.

Our results showed a significant relief of postoperative pain as indicated by the lower values of VAS and the significantly lower need for postoperative rescue analgesia in patients who received 
ketamine as adjuvant to bupivacaine. In agreement with our study, Lashgarinia et al., (2014) [16] who studied the effect of ketamine as an adjuvant in ultrasound-guided supraclavicular brachial plexus block. Their results showed that, addition of ketamine $(2 \mathrm{mg} / \mathrm{kg})$ to lidocaine $1.5 \%$ in ultrasoundguided supraclavicular brachial plexus block results in decreasing post-operative pain and need for rescue analgesics. Abdel Dayem et al., [17] who compared the effect of ketamine versus morphine as adjuvant to bupivacaine in ultrasound guided stellate ganglion block in post mastectomy pain syndrome, their results showed that ultrasound guided stellate ganglion block using ketamine $(0.5 \mathrm{mg} / \mathrm{kg})$ as adjuvant to bupivacaine $(0.25 \%)$ successfully decreased pain VAS and reduced the need for analgesic drugs. Gamil et al., [18] who studied the effect of ketamine as an adjuvant to bupivacaine in spermatic cord block for testicular sperm extraction surgery and concluded that the addition of ketamine as an adjuvant to bupivacaine for spermatic cord block is a good option for postoperative pain control as it prolongs the duration of pain-free time and lowers the VAS score. Kulkarni et al., [19], who studied the effect of ketamine as an adjuvant to the local anaesthetic for Stellate Ganglion Block (STGB) in cases of peripheral vascular disease of upper limbs. They observed complete healing of the gangrenous fingers in 17/19 patients, Stellate Ganglion Block (STGB) using local anaesthetic with an adjuvant ketamine is a safe and effective technique. Ketamine enhances the effect of sympathetic blockade with relief of pain lowering VAS score, ischaemia and maintains circulation.

In disagreement with our results, Rahimzadeh et al., [20] who studied the effectiveness of adding ketamine to ropivacaine infusion via femoral nerve catheter after elective knee surgery for repairing anterior cruciate ligament under spinal anaesthesia, they reported that the addition of ketamine $1 \mathrm{mg} / \mathrm{kg}$ to $0.1 \%$ ropivacaine could not improve postoperative pain relief in the first 48 hours after the operation and this may be due to the lower concentration of ropivacaine $(0.1 \%)$ and the lower dose of ketamine $1 \mathrm{mg} / \mathrm{kg}$ compared to that of the present study ( $0.5 \%$ bupivacaine and $2 \mathrm{mg} / \mathrm{kg}$ ketamine). Rosseland et al., [21] who found that addition of ketamine (10mg) to local anaesthetics failed to improve analgesia after intra-articular injection for post arthroscopy pain. The variable effect of ketamine in Rosseland study probably came from the route of administration (intra-articular) and the smaller dose (10mg in their study compared with $2 \mathrm{mg} / \mathrm{kg}$ in the present study) and the five folds dilutation of ketamine. Zohar et al., [22] reported that ketamine added to local bupivacaine $(0.125 \%)$ did not enhance analgesia after wound infiltration following Cesarean section. The variable effect of ketamine in their study may be due to four folds dilutation of bupivacaine used, while in the present study we use bupivacaine $(0.5 \%)$.

With respect to the duration of sensory block in our study, there was statically significant longer duration in Group II compared with Group I. The longer duration in the ketamine group may be explained by the possibility that Ketamine might increase the binding capacity of local anaesthetic to albumin alpha acid glycoprotein and change ionic balance. Another mechanism might be due to two isomers ( $\mathrm{S})$ and $(\mathrm{R})$ : $\mathrm{S}$ isomer blocks the opiate receptors and $\mathrm{R}$ isomer has hypnotic effects [23]. In agreement with our study in the study of Noyan [24] who studied the effect of ketamine in axillary block in hand surgery. His study showed that patients who received ketamine had rapid onset and long anaesthesia time. The study concluded that ketamine enhanced the activity of local anaesthetic, so it shortened the onset and prolonged the duration of action. Grupp et al., [25] the study conducted by comparing the effect of adrenaline, clonidine and ketamine on the duration of caudal analgesia produced by bupivacaine in children and concluded that the addition of ketamine $0.5 \mathrm{mg} / \mathrm{kg}$ or clonidine $2 \mathrm{mg} / \mathrm{kg}$ to $0.25 \%$ bupivacaine prolonged the duration of action of caudal block more than adrenaline 1/200 000 .

In contrast with our results, Senel et al., [26] who compared the effect of addition of tramadol or ketamine to ropivacaine in axillary brachial plexus block in patients scheduled for forearm and hand surgery under axillary brachial plexus block. The results showed that addition of 50mg ketamine to $0.375 \%$ ropivacaine did not provide any additional effect on axillary brachial plexus. They postulated that the possible cause of this may be the low concentration of $50 \mathrm{mg}$ ketamine in a volume of $40 \mathrm{ml}$, also they used lower dose compared to our study. Lee et al., [27] who studied the effect of adding ketamine to ropivacaine in patients scheduled for forearm or hand surgery receiving interscalene brachial plexus. They concluded that $30 \mathrm{mg}$ ketamine added to $30 \mathrm{ml}$ of $0.5 \%$ ropivacaine in the brachial plexus block, did not improve the onset time or duration of sensory and motor block. They explained their results by suggesting that the variable effect of ketamine probably comes from the different ketamine concentration and sites of injection they used lower dose (30mg compared to $2 \mathrm{mg} / \mathrm{kg}$ ketamine) in the present study. 
As regard to post-operative complication, the result of our study showed no recorded hypotension, bradycardia, headache, urine retention or hallucination in the two groups. While regarding PONV were presented only in two patients in Group I and five patients in Group II and they were treated with ondansterone $0.1 \mathrm{mg} / \mathrm{kg}$. In agreement with our study Subramaniam et al., [28] evaluated the safety and efficacy of epidural ketamine combined with morphine for postoperative analgesia after major upper abdominal surgery and concluded that the addition of epidural ketamine $1 \mathrm{mg} / \mathrm{kg}$ to morphine $50 \mu \mathrm{g} / \mathrm{kg}$ improved analgesia after major upper abdominal surgery without increasing side effects.

In contrast with our study, Lee et al., [27] who reported a relatively higher incidence of psychomimetic sequelae (unpleasant feeling, bad dreams, hallucinations, altered short-term memory, distortion of body image and drowsiness) which were mainly of central origin. Those adverse effects were transient, of short duration (maximal duration was $25 \mathrm{~min}$ in one patient) and did not require any therapeutic intervention. They suggested that ketamine gains entrance into the central circulation after interscalene brachial plexus blockade to produce a high incidence of unpleasant psychomimetic sequelae.

\section{Conclusion:}

In patient undergoing inguinal hernia repair surgery addition of ketamine $2 \mathrm{mg} / \mathrm{kg}$ to bupivacaine in ultrasound guided ilioinguinal and iliohypogastric nerve block produce more effective postoperative analgesia as indicated by lower VAS scale and prolonged duration of sensory block compared to bupivacaine alone.

\section{Conflicts of interest:}

No conflicts of interest declared.

\section{Authors' contributions:}

All authors had equal role in design, work, statistical analysis and manuscript writing.

\section{References}

1- LASHGARINIA M., NAGHIBI K., HONARMAND A., SAFAVI M. and KHAZAEI M.: Effect of ketamine as an adjuvant in ultrasound-guided supraclavicular brachial plexus block: A double-blind randomized clinical trial study. Adv. Biomed. Res., 3: 232, 2014.

2- ABDEL DAYEM O.T., SAEID M.M., ISMAIL O.M., ELBADRAWY A.M. and ABDEL GHAFFAR N.A.: Ultrasound guided stellate ganglion block in postmastectomy pain syndrome: A comparison of ketamine versus morphine as adjuvant to bupivacaine. J. Anesth., 11-5, 2014.
3- GAMIL K. and FATHY A.: Spermatic cord block with ketamine as an adjuvant to bupivacaine improves postoperative analgesia for testicular sperm extraction surgery. Ain-Shams J. of Anesth., 6: 153-7, 2013.

4- KULKARNI K.R., KADAM A.I. and NAMAZI I.J.: Efficacy of stellate ganglion block with an adjuvant ketamine for peripheral vascular disease of the upper limbs. Indian J. Anaesth., 564: 551-6, 2010.

5- DAL D., TETIC O., ALTUNKAYA H., TETIK O. and DORAL M.N.: The efficacy of intra-articular ketamine for post-operative analgesia in outpatient arthroscopic surgery. Arthroscopy, 20 (3): 300-5, 2004.

6- TVERSKOY M., OREN M., VASKOVICH M., DASHKOVSKY I. and KISSIN I.: Ketamine enhance local anesthetic and analgesic effects of bupivacaine by peripheral mechanism: A study in post-operative patients. Neurosci. Lett., 215: 5-8, 1996.

7- RAHIMZADEH P., FAIZ S.H., ZIYAEIFARD M. and NIKNAM K.: Effectivness of adding ketamine to ropivacaine infusion via femoral nerve catheter after knee anterior cruciate ligament repair. J. Res. Med. Sci., 18: 632-6, 2013.

8- ROSSELAND L.A., STUBHAUG A., SANDBERG L and BREIVIK H.: Intra-articular (IA) catheter administration of postoperative analgesics. A new trial design allows evaluation of baseline pain, demonstrates large variation in need of analgesics, and finds no analgesic effect of IA ketamine compared with IA saline. Pain, 104: $25-34,2003$

9- ZOHAR E., LUBAN I., ZUNSER I., SHAPIRO A., JEDEIKIN R. and FREDMAN B.: Patient-controlled bupivacaine wound instillation following cesarean section: The lack of efficacy of adjuvant ketamine. J. Clin. Anesth., 14: 505-11, 2002

10- WHITE P.F.: Ketamine update: Its clinical uses in anesthesia. In: Domino E.F. (ed). Status of Ketamine in Anesthesiology. Ann Arbor, MI: NPP Books; 1990 ". Quoted from Noyan A. On effects of ketamine to axillary block in hand surgery. J. Reconstr. Micro. Surg., 18 (3): 197-8, 2002.

11- NOYAN A.: On effects of ketamine to axillary block in hand surgery. J. Reconstr. Micro. Surg., 18 (3): 197-8, 2002.

12- GRUBB D.J., COOK B., ALDRIDGE L.A. and DOYLE E.: Comparison of the effects of adrenaline, clonidine and ketamine on the duration of caudal analgesia produced by bupivacaine in children. B. J. A., Dec. 1; 75 (6): 698701, 1995 .

13- CAN S.A., OZLEM U.O. and TIMUR K.A.: Does the addition of tramadol and ketamine to ropivacaine prolong the axillary brachial plexus block? Biomed. Res. Int., 2014 (686287): 1-5, 2014

14- LEE I.O., KIM W.K., KONG M.H., LEE M.K., KIM N.S. and CHOI Y.S.: No enhancement of sensory and motor blockade by ketamine added to ropivacaine interscalene brachial plexus blockade. Acta Anaesthesiol. Scandin., 46: 821-6, 2002.

15- SUBRAMANIAM K., SUBRAMANIAM B., PAWAR D.K. and KUMAR L.E.: Valuation of the safety and efficacy of epidural ketamine combined with morphine for post-operative analgesia after major upper abdominal surgery. J. Clini. Anesth., 13 (5): 339-44, 2001. 
16- LASHGARINIA M., NAGHIBI K., HONARMAND A., SAFAVI M. and KHAZAEI M.: Effect of ketamine as an adjuvant in ultrasound-guided supraclavicular brachial plexus block: A double-blind randomized clinical trial study. Adv. Biomed. Res., 3: 232, 2014.

17- ABDEL DAYEM O.T., SAEID M.M., ISMAIL O.M., ELBADRAWY A.M. and ABDEL GHAFFAR N.A.: U1trasound guided stellate ganglion block in postmastectomy pain syndrome: A comparison of ketamine versus morphine as adjuvant to bupivacaine. J. Anesth., 11-5, 2014.

18- GAMIL K. and FATHY A.: Spermatic cord block with ketamine as an adjuvant to bupivacaine improves postoperative analgesia for testicular sperm extraction surgery. Ain-Shams J. of Anesth., 6: 153-7, 2013.

19- KULKARNI K.R., KADAM A.I. and NAMAZI I.J.: Efficacy of stellate ganglion block with an adjuvant ketamine for peripheral vascular disease of the upper limbs. Indian J. Anaesth., 564: 551-6, 2010.

20- RAHIMZADEH P., FAIZ S.H., ZIYAEIFARD M. and NIKNAM K.: Effectivness of adding ketamine to ropivacaine infusion via femoral nerve catheter after knee anterior cruciate ligament repair. J. Res. Med. Sci., 18: 632-6, 2013.

21- ROSSELAND L.A., STUBHAUG A., SANDBERG L. and BREIVIK H.: Intra-articular (IA) catheter administration of post-operative analgesics. A new trial design allows evaluation of baseline pain, demonstrates large variation in need of analgesics, and finds no analgesic effect of IA ketamine compared with IA saline. Pain, 104: 25-34, 2003.

22- ZOHAR E., LUBAN I., ZUNSER I., SHAPIRO A., JE-
DEIKIN R. and FREDMAN B.: Patient-controlled bupivacaine wound instillation following cesarean section: The lack of efficacy of adjuvant ketamine. J. Clin. Anesth., 14: 505-11, 2002

23- WHITE P.F.: Ketamine update: Its clinical uses in anesthesia. In: Domino EF(ed). Status of Ketamine in Anesthesiology. Ann Arbor, MI: NPP Books; 1990 ". Quoted from Noyan A. On effects of ketamine to axillary block in hand surgery. J. Reconstr. Micro. Surg., 18 (3): 197-8, 2002.

24- NOYAN A.: On effects of ketamine to axillary block in hand surgery. J. Reconstr. Micro. Surg., 18 (3): 197-8, 2002.

25- GRUBB D.J., COOK B., ALDRIDGE L.A. and DOYLE E.: Comparison of the effects of adrenaline, clonidine and ketamine on the duration of caudal analgesia produced by bupivacaine in children. B. J. A. Dec. 1; 75 (6): 698$701,1995$.

26- CAN S.A., OZLEM U.O. and TIMUR K.A.: Does the addition of tramadol and ketamine to ropivacaine prolong the axillary brachial plexus block? Biomed. Res. Int., 2014 (686287): 1-5, 2014.

27- LEE I.O., KIM W.K., KONG M.H., LEE M.K., KIM N.S. and CHOI Y.S.: No enhancement of sensory and motor blockade by ketamine added to ropivacaine interscalene brachial plexus blockade. Acta Anaesthesiol. Scandin, 46: 821-6, 2002.

28- SUBRAMANIAM K., SUBRAMANIAM B., PAWAR D.K. and KUMAR L.E.: Valuation of the safety and efficacy of epidural ketamine combined with morphine for postoperative analgesia after major upper abdominal surgery. J. Clini. Anesth., 13 (5): 339-44, 2001.

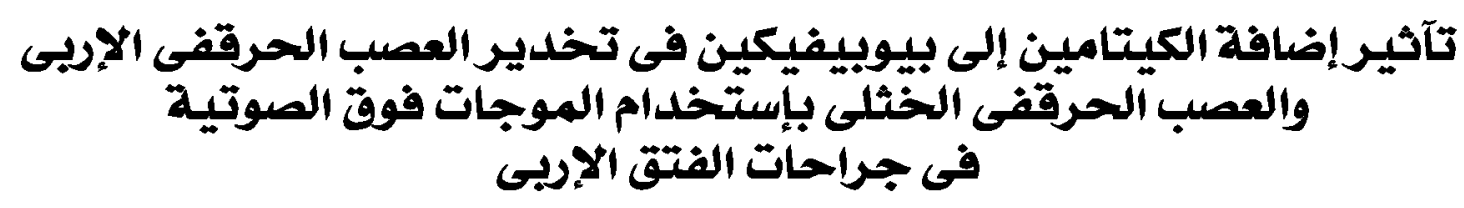

$$
\begin{aligned}
& \text { إصلاح القتق الإبى هـ واحدة من آكثر العمليات الجراحية شيوعا فى العالم وعدم التحكم فى الالم بعد الجراحة هو عامل مهم لإستمرار }
\end{aligned}
$$

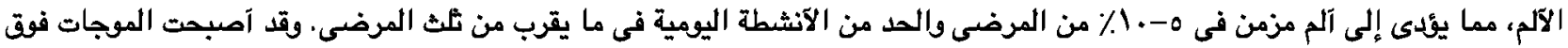

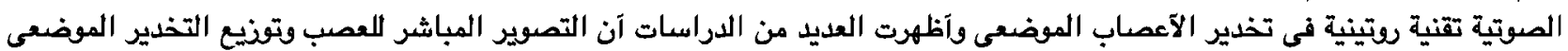

$$
\begin{aligned}
& \text { مع إستخدام مسبار عالى التردد يمكن آن تصسن نوية التخدير ويساعد على تجنب مضاعي الاعفات الجراحة. }
\end{aligned}
$$

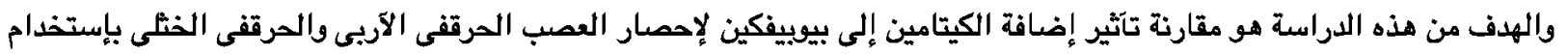

$$
\begin{aligned}
& \text { الموجات فوق الصوتية في المرضى الخاضعين لعمليات الفتق الإربى. } \\
& \text { وإستتجنا آن إضـافة الكيتامين بجرعة ب مللى جرام كجم إلى البيوبيفكين فى إحصار العصب الحرقفى الإربى والحرقفى الخثلى بإستخدام }
\end{aligned}
$$

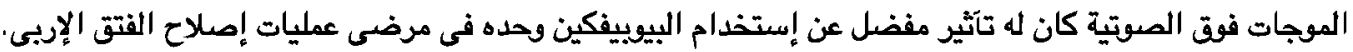

